\title{
Accuracy of a Pulse-Coherent Acoustic Doppler Profiler in a Wave-Dominated Flow
}

\author{
JESSICA R. LACY \\ U.S. Geological Survey, Santa Cruz, California
}

CHRistopher R. SHERwoOd

U.S. Geological Survey, Woods Hole, Massachusetts

(Manuscript received 9 May 2003, in final form 4 February 2004)

\begin{abstract}
The accuracy of velocities measured by a pulse-coherent acoustic Doppler profiler (PCADP) in the bottom boundary layer of a wave-dominated inner-shelf environment is evaluated. The downward-looking PCADP measured velocities in eight $10-\mathrm{cm}$ cells at $1 \mathrm{~Hz}$. Velocities measured by the PCADP are compared to those measured by an acoustic Doppler velocimeter for wave orbital velocities up to $95 \mathrm{~cm} \mathrm{~s}^{-1}$ and currents up to 40 $\mathrm{cm} \mathrm{s}^{-1}$. An algorithm for correcting ambiguity errors using the resolution velocities was developed. Instrument bias, measured as the average error in burst mean speed, is $-0.4 \mathrm{~cm} \mathrm{~s}^{-1}$ (standard deviation $=0.8$ ). The accuracy (root-mean-square error) of instantaneous velocities has a mean of $8.6 \mathrm{~cm} \mathrm{~s}^{-1}$ (standard deviation $=6.5$ ) for eastward velocities (the predominant direction of waves), $6.5 \mathrm{~cm} \mathrm{~s}^{-1}$ (standard deviation $=4.4$ ) for northward velocities, and $2.4 \mathrm{~cm} \mathrm{~s}^{-1}$ (standard deviation $=1.6$ ) for vertical velocities. Both burst mean and root-meansquare errors are greater for bursts with $u_{b} \geq 50 \mathrm{~cm} \mathrm{~s}^{-1}$. Profiles of burst mean speeds from the bottom five cells were fit to logarithmic curves: $92 \%$ of bursts with mean speed $\geq 5 \mathrm{~cm} \mathrm{~s}^{-1}$ have a correlation coefficient $R^{2}>0.96$. In cells close to the transducer, instantaneous velocities are noisy, burst mean velocities are biased low, and bottom orbital velocities are biased high. With adequate blanking distances for both the profile and resolution velocities, the PCADP provides sufficient accuracy to measure velocities in the bottom boundary layer under moderately energetic inner-shelf conditions.
\end{abstract}

\section{Introduction}

The ability to measure high-resolution velocity profiles greatly facilitates the study of bottom boundary layer dynamics, which are critical to both sediment resuspension and turbulence generation. For example, the accurate fitting of a logarithmic profile depends strongly on the number of velocity measurements in the bottom boundary layer (Gross and Nowell 1983). Many studies of the bottom boundary layer have used arrays of singlepoint velocimeters (Cacchione and Drake 1982; Grant et al. 1984; Drake et al. 1992). The number of velocimeters is usually at most five because of physical constraints in positioning the current meters and the need to limit flow disturbance. Acoustic Doppler profilers minimize the flow disturbance, but with broadband profilers the minimum size of the cell does not provide adequate resolution in the near-bed region. With pulsecoherent Doppler technology the minimum cell size is an order of magnitude smaller. This technology has recently become commercially available, promising the

Corresponding author address: Jessica Lacy, U.S. Geological Survey, Pacific Science Center, 400 Natural Bridges Drive, Santa Cruz, CA 95060.

E-mail: jlacy@usgs.gov capability to collect high-resolution, high-frequency velocity profiles over a short range (Lhermitte and Serafin 1984; Lohrmann et al. 1990; Zedel et al. 1996). The profiling range for pulse-coherent systems is practically limited to $1-2 \mathrm{~m}$ because it is inversely proportional to the maximum measurable velocity.

Field testing of pulse-coherent acoustic Doppler profilers (PCADPs) has been limited, particularly in wavedominated flows. The sources of error inherent in the pulse-coherent technique have been investigated and described by Zedel et al. (1996) and Hurther and Lemmin (2001). They include ambiguity in the Doppler phase shift (discussed in section 4); effects related to the size of the sampling volume, including spatial averaging, velocity shear, and turbulence at scales smaller than the sampling volume; near-field acoustic effects due to variation in phase across the beam; and sampling error in the electronic circuitry. The noise level in turbulence statistics calculated from data taken with acoustic Doppler current profilers (ADCPs) in the pulse-coherent mode is much higher than for acoustic Doppler velocimeters (ADVs), because the sampling volume for the $\mathrm{ADCP}$ is much larger than for the ADV and is located in multiple beams. (Nystrom et al. 2003). In the ADCP, velocity fluctuations from different turbulent eddies are 
combined in the measurement of velocity at a given depth, because of the spatial separation of the beams. In addition, in both the ADCP and the ADV, alongbeam noise is magnified by the conversion to horizontal coordinates (Hurther and Lemmin 2001). Previous field applications of ADCPs in the pulse-coherent mode include measurements of velocity profiles to calculate bottom shear stress and roughness in a tidal flow (Cheng et al. 1999), and evaluation of velocities near the transducer in a unidirectional flow in a constructed channel (Gartner and Ganju 2003).

Measurement of velocity profiles in a wave-dominated or oscillatory flow requires a high degree of accuracy because of the rapidly varying current speed and direction. In measurement of unidirectional or mean flow, accuracy is increased by averaging multiple profiles. For example, the single-ping accuracy of a 1.5$\mathrm{MHz}$ Sontek acoustic Doppler profiler with a cell size of $1 \mathrm{~m}$ is $\pm 14 \mathrm{~cm} \mathrm{~s}^{-1}$, and Sontek (2000) recommends a 25-s averaging period to achieve an accuracy of \pm 1 $\mathrm{cm} \mathrm{s}^{-1}$. Resolution of typical surface gravity waves on the inner shelf requires sampling rates of $1 \mathrm{~Hz}$ or higher, which restricts the number of pings that can be collected and averaged.

In this paper we report velocity profiles collected with a Sontek PCADP in the bottom boundary layer off the coast of southwest Washington. A wide range of conditions occurred during the deployment, including currents up to $40 \mathrm{~cm} \mathrm{~s}^{-1}$ and representative wave orbital velocities up to $95 \mathrm{~cm} \mathrm{~s}^{-1}$. We review the principles of pulse-coherent acoustic Doppler profilers, and evaluate the accuracy of the PCADP by comparing velocities in midprofile to those measured by a Sontek field acoustic Doppler velocimeter (ADVF). The ADVF provides a highly accurate measurement of three components of velocity at one location at frequencies up to $25 \mathrm{~Hz}$. We then evaluate the accuracy of mean profiles by comparing them to logarithmic profiles.

Our goal is to evaluate the performance of the PCADP for investigating the dynamics of the bottom boundary layer in wave-dominated environments. This application requires a minimum profiling range of $\sim 1 \mathrm{~m}$ and a sampling frequency of no less than $1 \mathrm{~Hz}$. Our data allow us to empirically characterize the accuracy of the instrument for this application, but not to fully analyze the causes of the observed errors. Although we sampled a fairly wide range of flow conditions, the reported errors may not be generalizable to other applications or environments.

\section{Data collection}

An instrumented tripod was deployed on the ebb-tidal delta of Grays Harbor, Washington, during the summer of 2001 to measure currents, waves, and suspended sediment, in a mean water depth of $9 \mathrm{~m}$. The tripod was deployed on 4 May and was recovered on 11 July, with one turnaround 6-8 June to change batteries, recover data, and clean sensors. The Washington coast is characterized by rough wave conditions and large tides, with the tidal range exceeding $3 \mathrm{~m}$ during spring tides. Currents are primarily wind driven. In summer, significant wave heights are typically $1-2 \mathrm{~m}$, and reach $4 \mathrm{~m}$ during periods of strong southerly winds. Currents reached 40 $\mathrm{cm} \mathrm{s}^{-1}$ and bottom orbital velocities approached 100 $\mathrm{cm} \mathrm{s}^{-1}$ during the experiment (Fig. 1).

A $1.5-\mathrm{MHz}$ Sontek PCADP was mounted on the tripod looking downward to measure velocity profiles in the bottom meter above the bed. The PCADP measured velocity in eight $10-\mathrm{cm}$ (nominal) cells, at $1 \mathrm{~Hz}$. The PCADP allows cell sizes as small as $2 \mathrm{~cm}$, but we found during initial testing that the noise level for cell sizes close to $2 \mathrm{~cm}$ was unacceptably high for measuring wave velocities. The PCADP sampled for 20-min bursts every hour. Other sampling parameters for the PCADP are shown in Table 1. A Paros Scientific Digiquartz pressure sensor connected to the PCADP measured pressure at $1 \mathrm{~Hz}$.

A $10-\mathrm{MHz}$ Sontek ADVF was mounted on the tripod to verify the velocities measured by the PCADP. The ADVF sampled at $20 \mathrm{~Hz}$ for a 20-min burst every 120 min at a height of $72 \mathrm{~cm}$ during the first deployment, and at $10 \mathrm{~Hz}$ for a 20 -min burst every $60 \mathrm{~min}$ at a height of $78 \mathrm{~cm}$ during the second deployment. In both deployments the ADVF sampling volume was located near the top of cell 5 of the PCADP.

East and north components of the wave velocities $u_{e w}$ and $u_{n w}$ were calculated by subtracting the burst mean from the instantaneous east and north velocities $u_{e}$ and $u_{n}: u_{e w}=u_{e}-\bar{u}_{e}, u_{n w}=u_{n}-\bar{u}_{n}$. The predominant direction of wave propagation was to the east. To characterize the amplitude of wave velocities in a burst we calculated

$$
u_{b}=\sqrt{2} \operatorname{std}\left(u_{w}\right),
$$

where $u_{w}$ is the component of wave velocity in the principal direction of the waves (the direction with maximum variance in $u_{w}$ for each burst). We refer to $u_{b}$ as the bottom orbital velocity; note that this definition of $u_{b}$ differs from that given by Madsen (1994).

\section{Coordinate systems}

Three coordinate systems are used in comparing the velocities measured by the PCADP and the ADVF: beam, $x y z$, and earth. In beam coordinates the three components of velocity are in the direction of the three PCADP beams, which are $15^{\circ}$ off vertical at $120^{\circ}$ horizontal spacing. ADVF data shown in beam coordinates in this paper have been converted to PCADP beam coordinates. In $x y z$ coordinates the $z$ direction points from the measurement volume toward the transducer along the axis of the instrument, the $x$ direction is the heading of beam 1 in the plane perpendicular to the $z$ axis, and $y$ is chosen to be perpendicular to $x$ in the same plane 

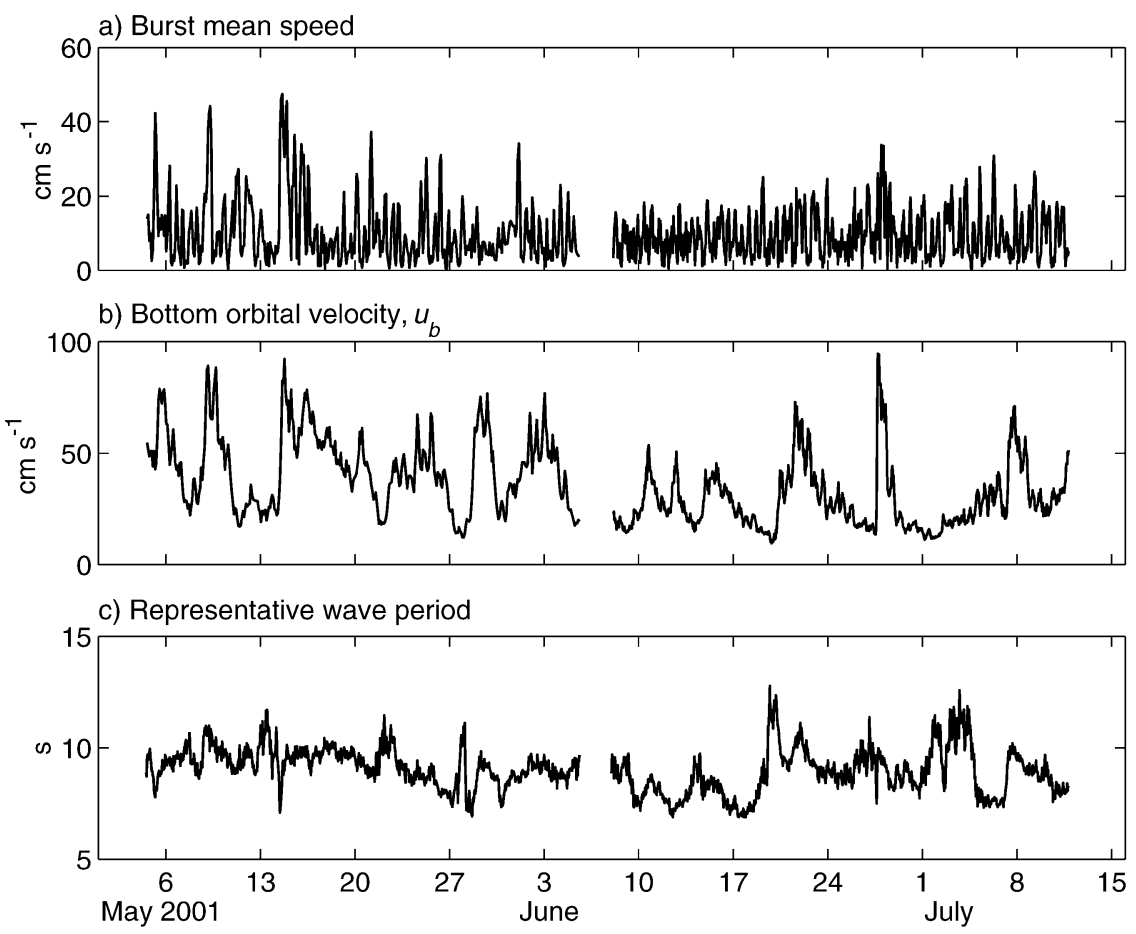

FIG. 1. Time series of (a) burst mean speed $\bar{s}$, (b) bottom orbital velocity $u_{b}$, and

(c) representative wave period measured by the ADVF.

to make a right-handed coordinate system. The $x$ directions of the PCADP and the ADVF were visually aligned on the tripod (to within approximately $2^{\circ}$ ), so velocities in the $x y z$-coordinate system $\left(V_{x}, V_{y}\right.$, and $\left.V_{z}\right)$ measured by the two instruments can be directly compared. Velocities in earth coordinates-east, north, and vertical $\left(V_{e}, V_{n}\right.$, and $\left.V_{u}\right)$-result from rotating $V_{x}, V_{y}$, and $V_{z}$ based on the heading, pitch, and roll recorded by the instrument, and correcting for local magnetic declination $\left(19^{\circ}\right.$ east $)$.

TABLE 1. PCADP sampling parameters. Distances are vertical, not along beam. Units are those used in PCADP commands; number of significant figures is that provided in PCADP control file. Profiling lag and resolution lag are the Sontek commands for specifying profiling and resolution pulse ranges.

\begin{tabular}{lcc}
\hline \hline \multicolumn{1}{c}{ Parameter } & Deployment 1 & Deployment 2 \\
\hline No. cells & 8 & 8 \\
Cell size (cm) & 10.8 & 9.4 \\
Blanking distance (cm) & 10 & 10 \\
Profiling interval (s) & 1 & 1 \\
Burst interval (s) & 3600 & 3600 \\
Profiles per burst & 1200 & 1200 \\
Profiling lag (m) & 1.09 & 0.97 \\
Resolution lag (m) & 0.49 & 0.49 \\
Resolution blanking distance (m) & 0.24 & 0.24 \\
Max horizontal velocity (cm s $\left.{ }^{-1}\right)$ & \pm 64 & \pm 72 \\
Max horizontal velocity with & & \\
$\quad$ ambiguity resolution (cm s & \\
Pings per profile & \pm 143 & \pm 143 \\
\hline
\end{tabular}

\section{Pulse-coherent Doppler velocity profilers}

Single-pulse Doppler profilers measure the shift in frequency between an emitted acoustic signal and its reflection off particles in the water, and use the Doppler principle to determine along-beam water velocity $v$ from the frequency shift. The maximum profiling range is a function of the frequency $f$ of the emitted pulse, for example, $3.6 \mathrm{~m}$ for a 3-MHz unit and $100 \mathrm{~m}$ for a 500$\mathrm{kHz}$ unit (Sontek 2000). To detect a frequency shift $\Delta f$ requires a pulse duration $\Delta t$ such that $\Delta f \times \Delta t$ is on the order of one cycle. We want to measure water velocities that are four orders of magnitude smaller than the speed of sound in water $\left(c \sim 1500 \mathrm{~m} \mathrm{~s}^{-1}\right)$. For $f$ $=1 \mathrm{MHz}$ and a relative frequency shift $\Delta f / f=v / c$ of $10^{-4}$, the required pulse duration is about $10^{-2} \mathrm{~s}$. The spatial resolution $(\Delta z=c \Delta t)$ corresponding to such a pulse length is on the order of $10 \mathrm{~m}$ (Fig. 2). In practice, single-pulse Doppler profilers achieve spatial resolutions of about $1 \mathrm{~m}$ by using a range of frequencies and overlapping bins.

Many applications, including the measurement of velocity profiles in the bottom boundary layer, require higher spatial resolution (smaller cell or bin size) than provided by single-pulse systems. Pulse-coherent systems achieve higher spatial resolution $(\Delta z$ of several $\mathrm{cm})$ by using a pair of much shorter pulses $(\Delta t \sim$ $\left.10^{-5} \mathrm{~s}\right)$. The instrument emits the pulses a short time $\tau$ $\gg \Delta t$ apart, and measures the phase shift between the reflected signal at time $t$ and at time $t+\tau$. If the along- 


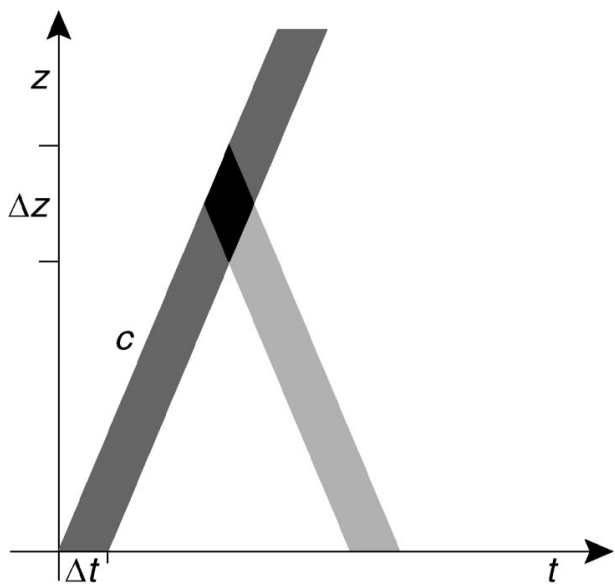

FIG. 2. Single-pulse method. A Doppler profiler emits an acoustic pulse and measures the frequency shift of the signal reflected from particles moving in the water. The emitted pulse (dark gray band) has duration $\Delta t$ and speed $c$ in the direction $z$. The signal received over an interval $\Delta t$ (light gray band) is reflected by particles in a range of length $\Delta z=c \Delta t$ (black diamond).

beam water velocity is $v$, the reflecting particles in the water travel an along-beam distance $v \tau$ during the interval $\tau$ (Fig. 3). The travel time of the second pulse, from the transducer to the particle and back, therefore differs from that of the first by $2 v \tau / c$, which means that the two reflected pulses are offset in phase by $2 \pi f \times$ $2 v \tau / c$. The instrument measures this phase shift $\Delta \phi$ between the reflected signal at times $t$ and $t+\tau$ to determine the velocity: $v=c \Delta \phi / 4 \pi f \tau=\lambda \Delta \phi / 4 \pi \tau$, where $\lambda$ is the wavelength.

The phase shift is determined only up to a multiple of $2 \pi$, so the along-beam velocity derived from it is determined only up to a multiple of $c / 2 f \tau$. In other words, the pulse-coherent method cannot by itself distinguish between velocities $v$ and $v+k V_{a}$, where $k$ is any integer and $V_{a}=c / 2 f \tau$. The quantity $V_{a}$ is called the ambiguity velocity. For a phase shift $\Delta \phi$ with $-\pi$ $<\Delta \phi<\pi$, the computed velocity $v$ lies in the range $-V_{a} / 2<v<V_{a} / 2$; if the actual velocity is outside this range, the difference between the two is called an ambiguity error. Thus, the pulse-coherent method provides greater spatial resolution than the single-pulse method, but at the cost of introducing ambiguity errors (Lohrmann et al. 1990).

The maximum distance from the transducer at which velocities are measured is related to the interval $\tau$ by $r_{\max }=c \tau / 2$, because the second pulse is not emitted until the reflection from the first has been received from the farthest cell. Multiplying this relation by the definition of $V_{a}$ gives

$$
V_{a} r_{\max }=\frac{c^{2}}{4 f}=\frac{c \lambda}{4}
$$

(Lhermitte and Serafin 1984), which expresses the tradeoff between profiling range and ambiguity velocity inherent in the pulse-coherent method.

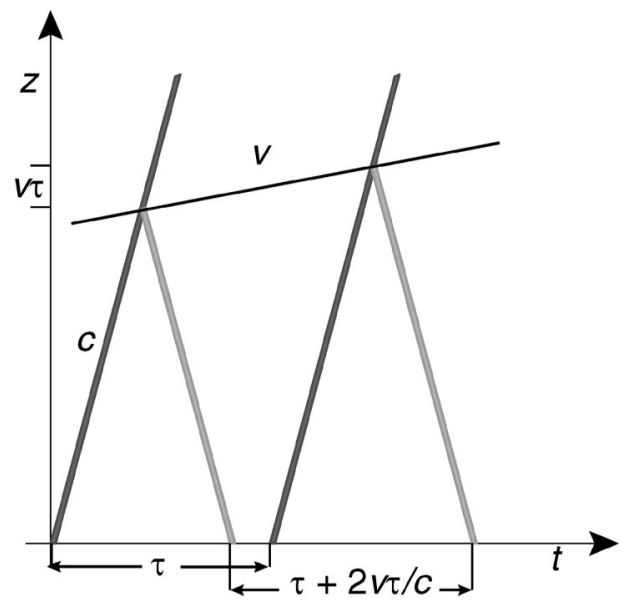

FIG. 3. Pulse-coherent method. During the interval $\tau$ between the two pulses, the along-beam distance $(z)$ of the scatterers from the transducer changes by $v \tau$, and the travel time to the scatterers and back changes by $2 v \tau / c$, where $c$ is the speed of sound in water and $v$ is the along-beam water velocity (shown exaggerated relative to $c$ ).

The error in single-ping measurements of the velocity is greater in the pulse-coherent than in the single-pulse method, because the shorter pulse samples only a fraction of turbulent fluctuations (Lhermitte and Serafin 1984). A number of pulse-pair measurements (pings) are averaged in each reported velocity profile, to decrease the error in the velocity (Table 1). The number of pings per profile and the signal-to-noise ratio are decreased by increasing the sampling frequency. Increasing the number of cells (either by decreasing the cell size or increasing the range) also decreases the number of pings per profile because the processing time for each ping increases. This trade-off between spatial or temporal resolution and noise level must be taken into account in selecting sampling parameters.

\section{Ambiguity error resolution}

Even in boundary layer applications where the profiling range is relatively short, the range of velocities that are measured unambiguously by pulse-coherent systems is too limited for many wave-dominated environments. For example, a $1-\mathrm{m}$ profiling range, $c=1500$ $\mathrm{m} \mathrm{s}^{-1}$, and $f=1.5 \mathrm{MHz}$ gives $V_{a} / 2=19 \mathrm{~cm} \mathrm{~s}^{-1}$. It follows that horizontal (as opposed to along beam) velocities outside the range $\pm 73 \mathrm{~cm} \mathrm{~s}^{-1}$ produce ambiguity errors, for a beam $15^{\circ}$ from vertical.

Sontek's approach to resolving ambiguity errors relies on a pulse pair, called the resolution pulse, emitted by the PCADP at the beginning of each set of profiling pings. It measures along-beam velocities in a $10-\mathrm{cm}$ cell at a user-specified distance that is less than the profiling range, so its ambiguity velocity is greater than that of the profiling pings [Eq. (2)]. The velocity measured by 
the resolution pulse (called the resolution velocity) is used to detect ambiguity errors in the profile velocities. In other words, it determines whether the true velocity is the reported velocity $v$ or $v+k V_{a}$ for an integer $k \neq$ 0 . Because the resolution velocity is only used to determine the value of $k$, the accuracy provided by a single pulse pair is sufficient. The resolution pulse extends the range of velocities that can be measured unambiguously, but if actual velocities exceed the ambiguity velocity of the resolution pulse, the error cannot, of course, be detected.

The resolution cell should, in principle, be as close as possible to the transducer because the ambiguity velocity is inversely proportional to the measurement range. In practice, we found that the resolution velocities were too noisy to reliably identify ambiguity errors if the resolution cell was too close to the transducer, perhaps due to acoustic near-field effects that cause decorrelation adjacent to the transducers (Zedel et al. 1996; see discussion in section 7). We used a resolution pulse with a blanking distance of $24 \mathrm{~cm}$ and a range of 49 $\mathrm{cm}$, which positions the resolution cell $24-34 \mathrm{~cm}$ from the transducer. The range must be greater than the maximum extent of the resolution cell to ensure separation of the reflections of the two pulses. The profiling range was approximately $1 \mathrm{~m}$, so the resolution pulse increased the range of measurable velocities by about a factor of 2 (Table 1).

Inspection of the resolution velocities showed frequent erroneous spikes that introduce errors into the profiling data when Sontek's ambiguity error correction procedure is applied. We developed an improved algorithm to identify and correct ambiguity errors. First, a low-pass filter with a cutoff frequency of $1 / 6 \mathrm{~Hz}$ is applied to the resolution velocities to eliminate erroneous spikes. Next, for each profile, the resolution velocity from each beam is compared to the recorded velocity for that beam in the cell closest to the resolution cell (cell 2 in our case), and if the two differ by more than $0.7 V_{a}$, the recorded velocity is corrected by $V_{a}$. Then, the corrected velocity is compared to the velocity in the adjacent cell, which is corrected by $V_{a}$ if necessary. The same procedure is used in comparing each pair of adjacent cells, first moving up through the profile and then moving down to the lowest cell. Thus, in the corrected measurements, velocities in two adjacent cells always differ by less than $V_{a}$. Sontek's algorithm also compares velocities in adjacent cells, but starts by comparing the resolution velocity to the recorded velocity in the top cell and moves down through the profile. Both methods assume that vertical shear does not produce velocity differences on the order of $V_{a}$ between adjacent cells because of the small cell size $(\sim 10 \mathrm{~cm})$.

After correcting ambiguity errors in each profile based on the resolution velocity, our method uses the time series within each burst to check for remaining ambiguity errors. A velocity is identified as erroneous if it differs from both the preceding and following ve- locities by more than $0.7 V_{a}$ and the two differences have opposite signs. These erroneous velocities are corrected by $V_{a}$. Finally, the measured velocities are converted from beam coordinates to $x y z$ and earth coordinates. The main differences between our algorithm and that provided by Sontek are the filtering of the resolution velocities and the use of the time series to identify ambiguity errors. Our algorithm corrected almost all of the ambiguity errors, but occasionally missed one or introduced a new error, as seen in Fig. 4 (beam 3, profile 146). Correction of ambiguity errors significantly reduced both burst mean and root-mean-square (rms) errors in velocities measured by the PCADP (defined in the following section), particularly for bursts with a bottom orbital velocity greater than $50 \mathrm{~cm} \mathrm{~s}^{-1}$ (Table 2).

\section{Comparison of burst statistics from PCADP and ADVF}

To evaluate the accuracy of the PCADP, we compared its measurements to those of the ADVF, which we assume to be true velocities. The ADVF was set to velocity range 4, which measures velocities up to $250 \mathrm{~cm} \mathrm{~s}^{-1}$ at an accuracy of $\pm 2.5 \mathrm{~cm} \mathrm{~s}^{-1}$ at $25 \mathrm{~Hz}$ (Sontek 1997). Averaging to $1 \mathrm{~Hz}$ produces an accuracy of approximately $\pm 0.6 \mathrm{~cm} \mathrm{~s}^{-1}$. The accuracy of the ADVF has been confirmed by laboratory testing: the ADVF measures mean flow speed to within $1 \%$ of that measured by a laser Doppler velocimeter (rms error $0.56 \mathrm{~cm} \mathrm{~s}^{-1}$ ), and accurately measures Reynolds stresses (to within $1 \%$ of ground-truth values; Voulgaris and Trowbridge 1998).

The first 118 of the 810 PCADP bursts of the second deployment have persistently low correlation $(<25 \%)$ in cells $1-3$, indicating poor data quality; these bursts were not analyzed further. We compared results from 385 synchronous bursts from deployment 1 and 692 synchronous bursts from deployment 2 (recall that the ADVF burst interval was $120 \mathrm{~min}$ in deployment 1 , and 60 min in deployment 2). Because the ADVF sampled at a higher frequency than the PCADP, the ADVF data were low-pass filtered (1-Hz cutoff) and subsampled at $1 \mathrm{~Hz}$ before calculating the statistics. The maximum cross correlation was found between each pair of PCADP and ADVF bursts to identify lags created by instrument clock drift, and each record was truncated to the interval of concurrent sampling. The relative clock drift noted at the times of retrieval agreed with the interval identified by the maximum cross correlation for the last burst pair for each deployment. The lag between the starts of the bursts from the two instruments increased monotonically during the deployment and never exceeded $60 \mathrm{~s}$.

We use two statistics to assess the accuracy of the PCADP: burst mean error and rms error. The burst mean error $e$ is calculated as 

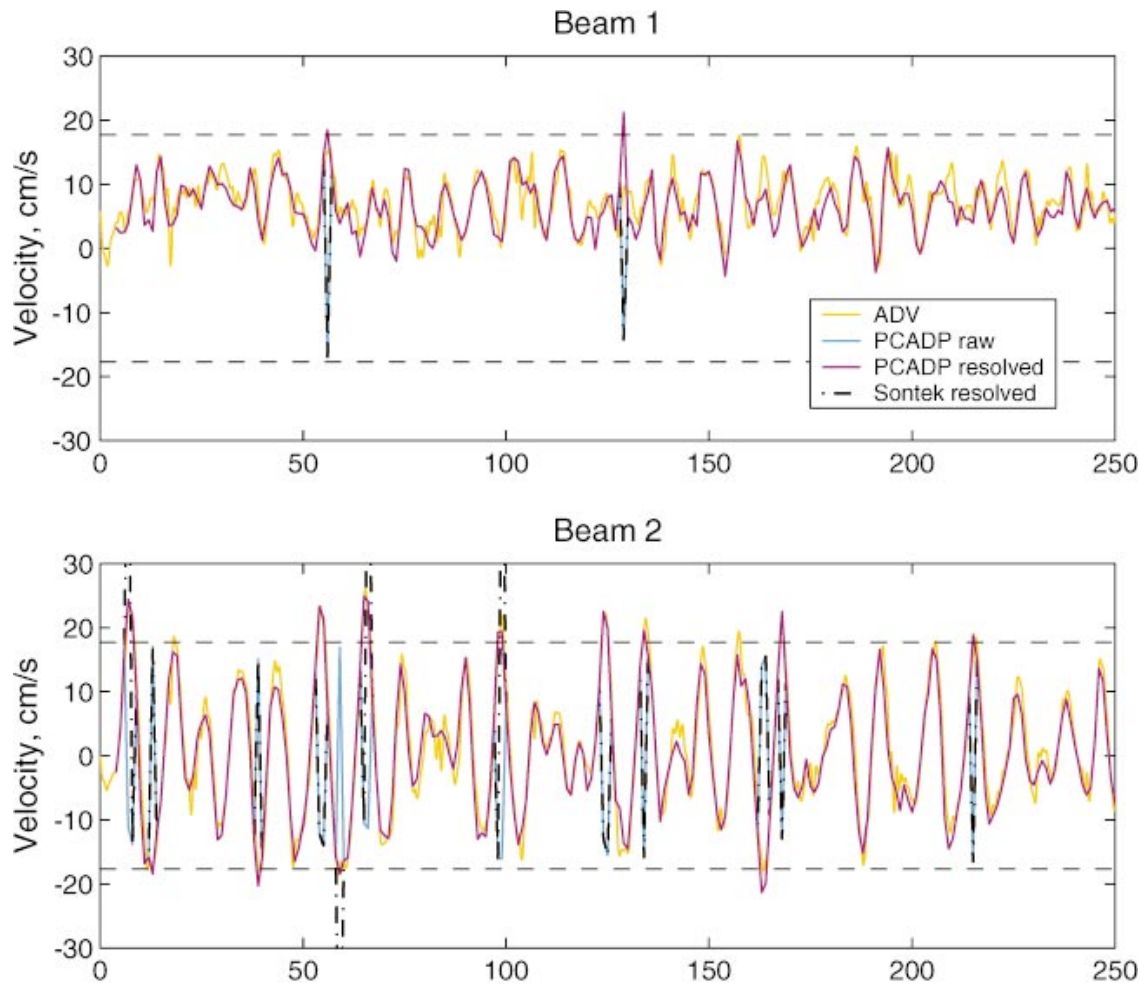

Beam 3

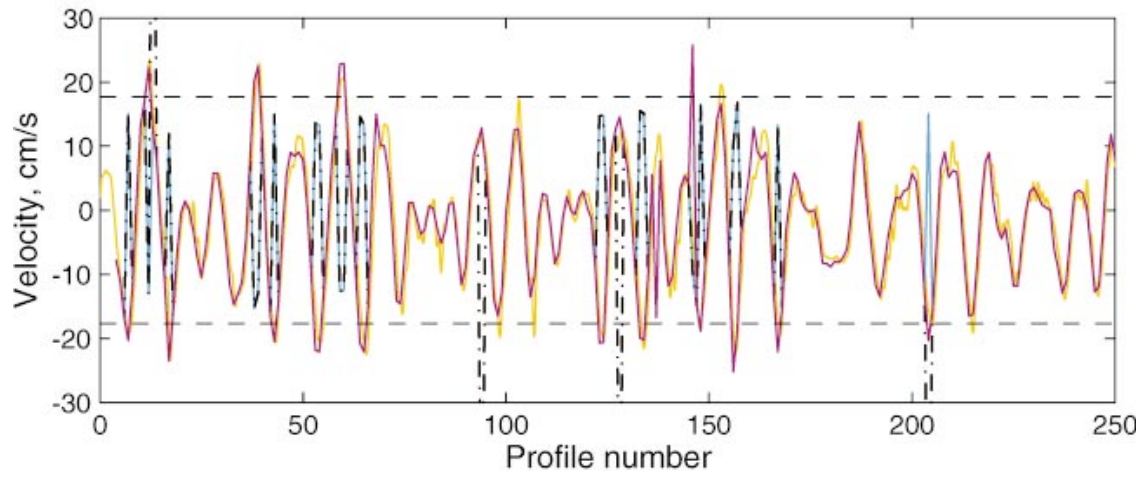

FIG. 4. Time series (within burst) for beams 1-3 from ADVF and cell 5 of PCADP, with no ambiguity resolution and with ambiguity resolution using our algorithm and Sontek's algorithm, in PCADP beam coordinates. Profiles were measured at $1 \mathrm{~Hz}$. Dashed horizontal lines are at $\pm V_{a} / 2$.

$$
e=\frac{1}{N} \sum_{i}\left(\mathrm{pc}_{i}-\mathrm{adv}_{i}\right)
$$

where pc is the measurement in cell 5 of the PCADP, $\mathrm{adv}$ is the value measured by the ADVF, $N$ is the number of profiles per burst (1200 in this case), and $i$ is the profile number within the burst. We calculated $e$ for three components of velocity and horizontal speed. The burst mean error is a measure of the bias in the PCADP measurements.

The rms error depends on the spread in the accuracy of the individual velocity measurements within the burst:

$$
\text { rms error }=\sqrt{\frac{1}{N} \sum_{i}\left(\mathrm{pc}_{i}-\mathrm{adv}_{i}\right)^{2} .}
$$

The rms error provides an estimate of the average accuracy of instantaneous velocities. The calculated rms errors for the PCADP are an order of magnitude greater than the error in the ADV velocity measurements at 1 $\mathrm{Hz}\left(\mathrm{adv}_{i}\right.$ ) (see first paragraph of this section and Fig. 11c), so that neglect of the error in $\mathrm{adv}_{i}$ in Eq. (4) does not significantly affect the results. The mean and standard deviation of burst mean and rms error were calculated for the 1043 synchronous bursts and are reported 
TABLE 2. Mean and std dev of burst mean error $(e)$ and $\mathrm{rms}$ error (in $\mathrm{cm} \mathrm{s}^{-1}$ ) with ambiguity error correction and without (italics).

\begin{tabular}{|c|c|c|c|c|c|c|}
\hline \multirow{2}{*}{$\begin{array}{l}\text { Velocity } \\
\text { component }\end{array}$} & \multicolumn{2}{|c|}{$\begin{array}{l}\text { All bursts } \\
N=1043\end{array}$} & \multicolumn{2}{|c|}{$\begin{array}{c}u_{b} \geq 50 \mathrm{~cm} \mathrm{~s}^{-1} \\
N=169\end{array}$} & \multicolumn{2}{|c|}{$\begin{array}{c}u_{b}<50 \mathrm{~cm} \mathrm{~s}^{-1} \\
N=874\end{array}$} \\
\hline & Mean & Std dev & Mean & Std dev & Mean & Std dev \\
\hline & \multicolumn{6}{|c|}{ Burst mean errors } \\
\hline \multirow[t]{2}{*}{ East } & -0.1 & 1.0 & 0.3 & 1.4 & -0.2 & 0.8 \\
\hline & 1.5 & 2.6 & 0.3 & 3.4 & 1.8 & 2.3 \\
\hline \multirow[t]{2}{*}{ North } & 0.3 & 0.8 & -0.1 & 1.0 & 0.4 & 0.7 \\
\hline & 0.4 & 2.8 & -1.2 & 5.1 & 0.7 & 2.0 \\
\hline \multirow[t]{2}{*}{ Vertical } & 0.1 & 0.6 & 0.4 & 0.9 & 0.0 & 0.5 \\
\hline & 0.2 & 0.7 & 1.0 & 1.0 & 0.1 & 0.5 \\
\hline \multirow[t]{3}{*}{ Horizontal speed } & -0.4 & 0.8 & -0.2 & 1.2 & -0.4 & 0.7 \\
\hline & -0.9 & 2.1 & -2.3 & 4.1 & -0.7 & 1.2 \\
\hline & \multicolumn{6}{|c|}{ Root-mean-square errors } \\
\hline \multirow[t]{2}{*}{ East } & 8.6 & 6.5 & 19.6 & 7.3 & 6.5 & 3.4 \\
\hline & 14.0 & 12.1 & 37.3 & 8.3 & 9.5 & 6.0 \\
\hline \multirow[t]{2}{*}{ North } & 6.6 & 4.4 & 13.8 & 5.0 & 5.2 & 2.5 \\
\hline & 10.5 & 6.1 & 20.5 & 6.0 & 8.5 & 3.8 \\
\hline \multirow[t]{2}{*}{ Vertical } & 2.4 & 1.6 & 4.8 & 1.9 & 1.9 & 0.9 \\
\hline & 2.6 & 1.7 & 5.5 & 1.4 & 2.1 & 1.0 \\
\hline
\end{tabular}

in Table 2. Table 2 also shows statistics for two subsets of bursts: those with bottom orbital velocity $u_{b}<50$ $\mathrm{cm} \mathrm{s}^{-1}$, and those with $u_{b} \geq 50 \mathrm{~cm} \mathrm{~s}^{-1}$. Bursts with $u_{b}$ $\geq 50 \mathrm{~cm} \mathrm{~s}^{-1}$ have a larger fraction of instantaneous velocities that are greater than $60 \mathrm{~cm} \mathrm{~s}^{-1}$ (Fig. 5) and thus are subject to ambiguity error. In 34 bursts, $2 \%$ or more of the instantaneous velocity measurements by the ADVF had a magnitude exceeding the ambiguity velocity for the resolution pulse $\left(\sim 120 \mathrm{~cm} \mathrm{~s}^{-1}\right)$, so that ambiguity error correction was not possible (Fig. 5). These velocities are outside the range of the PCADP (with the configuration shown in Table 1), and errors in these bursts are not representative of the accuracy of either the instrument or the ambiguity resolution algorithm. These bursts were not included in the calculation of the burst mean or rms error.

The mean error in burst mean speed is negative, in-

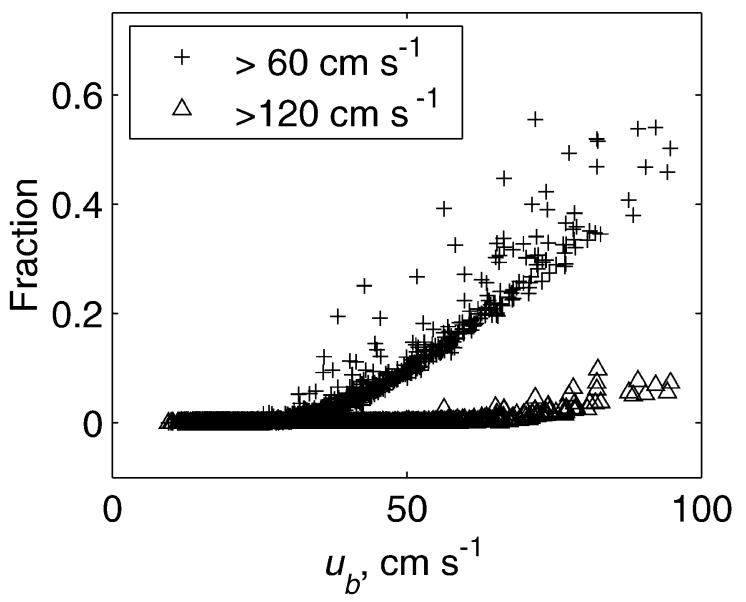

FIG. 5. Fraction of within-burst horizontal (ADVF) velocity magnitudes $>60 \mathrm{~cm} \mathrm{~s}^{-1}$ (crosses) and $>120 \mathrm{~cm} \mathrm{~s}^{-1}$ (triangles) vs bottom orbital velocity. dicating that the PCADP has a tendency to underestimate speed. However, the negative bias is small: for most bursts $(76 \%)$ the burst mean speeds measured by the PCADP and ADVF differ by less than $1 \mathrm{~cm} \mathrm{~s}^{-1}$ (Fig. 6 and Table 2). There is more spread in burst mean error for bursts with $u_{b} \geq 50 \mathrm{~cm} \mathrm{~s}^{-1}$. The rms error is $8.6 \mathrm{~cm} \mathrm{~s}^{-1}$ for east-west velocities and $6.6 \mathrm{~cm} \mathrm{~s}^{-1}$ for north-south velocities (Table 2). The greater rms error for east-west velocities is due to the greater wave-induced variance in this component (the principal direction of the waves was usually close to $90^{\circ}$ ). The rms error increases with $u_{b}$, and the rate of increase is higher for bursts with $u_{b} \geq 50 \mathrm{~cm} \mathrm{~s}^{-1}$ (Fig. 7). The standard deviation of rms error is significantly lower for bursts with $u_{b}<50 \mathrm{~cm} \mathrm{~s}^{-1}$ than for all bursts (Table 2). Ambiguity error resolution produced an average reduction of $\sim 35 \%$ in rms error. However, the relatively high rms error in the corrected PCADP velocities for bursts with $u_{b} \geq 50 \mathrm{~cm} \mathrm{~s}^{-1}$ indicate that the ambiguity correction was not completely effective.

Bottom orbital velocity calculated from PCADP cell 5 is quite accurate for $u_{b}<70 \mathrm{~cm} \mathrm{~s}^{-1}$ (Fig. 8b), and $u_{b}$ calculated from the ADVF and PCADP data are strongly correlated $\left(R^{2}=0.99\right.$, slope $\left.=1.04\right)$. The average error in the bottom orbital velocity $u_{b, \mathrm{PCADP}}-$ $u_{b, \mathrm{ADVF}}$ is $0.7 \mathrm{~cm} \mathrm{~s}^{-1}$ (std dev $=1.3$ ), indicating a slight positive bias (Fig. 8a). The variance in error in $u_{b}$ increases for bursts with $u_{b}>40 \mathrm{~cm} \mathrm{~s}^{-1}$ (Fig. 8b). For bursts with $2 \%$ or more velocities greater than 120 $\mathrm{cm} \mathrm{s}^{-1}$ the magnitude of error is substantially greater and the error is consistently negative, because ambiguity errors cannot be resolved in this range of velocities; these bursts were not included in the mean.

To compare the results of our ambiguity error correction algorithm with Sontek's, we calculated the burst mean error and rms error after applying each method to the first 35 bursts of the dataset (Table 3). For this 
subset of bursts, Sontek's method produced a small increase in both error statistics. One source of the increase in error is the occassional erroneous "corrections" of unambiguous velocities (as in Fig. 4, beam 3, profile 93), which occurs more frequently with the Sontek algorithm than with ours. Our method reduced rms errors in horizontal velocities by more than $30 \%$, and reduced the error in burst mean speed by $85 \%$. During the 35 bursts (4-7 May) waves and currents were energetic (Fig. 1), with $u_{b} \geq 50 \mathrm{~cm} \mathrm{~s}^{-1}$ for 15 of the bursts, so rms errors are higher than those in Table 2. The efficacy of Sontek's algorithm for other wave and current conditions cannot be generalized from this small sample. However, Table 3 demonstrates that our modifications to Sontek's ambiguity error correction method significantly improve the accuracy of the corrected data.

\section{Velocity profiles}

We rely on the law of the wall to make qualitative evaluations of the PCADP at elevations where we have no reference (ADVF) velocity measurements. The law of the wall predicts that mean speeds above the wave boundary layer are logarithmically distributed with respect to depth. To test the log-linearity of the burst mean speeds $\bar{s}$, we divided bursts into categories based on $\bar{s}$ in cell 5 . The averaging neglected variation in cell heights due to tripod settling and to the difference in cell size for the two deployments (Table 1). The 34 bursts with $2 \%$ or more instantaneous velocities greater than $120 \mathrm{~cm} \mathrm{~s}^{-1}$ were not included in the averaging.

The average profiles exhibit the expected logarithmic form, except in the cells closest to the transducer (Fig. 9). Logarithmic fits to average speeds in the bottom 5 cells have correlation coefficients $R^{2}>0.99$ for all except the slowest speed category. Close to the transducer the fit is not as good: speed in the first (top) cell is lower than predicted by the logarithmic fit for all but the slowest category. Speeds are also lower than expected in the second and third cells for categories with progressively lower burst mean speeds. For the slowest category of burst mean speed the correlation is lower $\left(R^{2}=0.95\right)$, apparent roughness is an order of magnitude less than for any other speed category, and speed in the top cell is greater, not less, than predicted (Fig. 9h). In this category, distortion of the logarithmic profile is likely due to burst mean error, which has a similar magnitude to the mean speeds (Table 2).

Possible sources for the decreased speeds close to the transducer are nonnormally distributed instrument noise, including near-field acoustic effects, and flow disturbance by the instrument or the tripod. Zedel et al. (1996) show that correlations are reduced close to the transducer due to cross-beam variation in phase when transverse (i.e., cross beam) velocities are significant. This near-field decorrelation is expected for ranges less than $a^{2} f / c$, where $a$ is the transducer radius. The
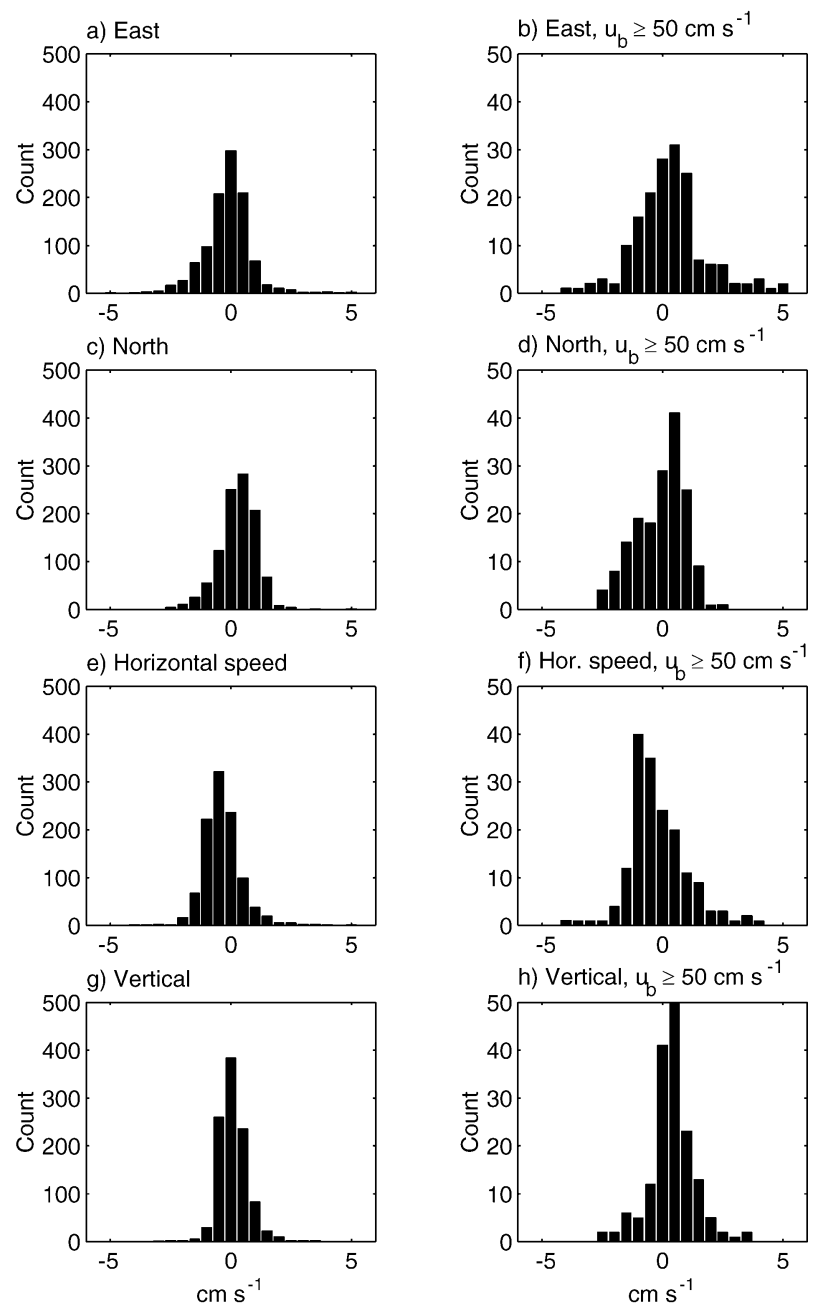

FIG. 6. Histograms of burst mean error for (left) 1043 bursts from the two deployments and for (right) 169 bursts with bottom orbital velocity greater than $50 \mathrm{~cm} \mathrm{~s}^{-1}$ for (a), (b) east velocity, (c), (d) north velocity, (e), (f) horizontal speed, and (g), (h) vertical velocity. Histogram bin interval is $0.5 \mathrm{~cm} \mathrm{~s}^{-1}$.

PCADP has $a=1.75 \mathrm{~cm}$, so the range of the near-field effect is $30 \mathrm{~cm}$. For our setup, this range extends into cell 2. The cell closest to the transducer (cell 1) was located $\sim 15-25 \mathrm{~cm}$ from the transducer [the distance of the center of cell $n$ from the transducer is the blanking distance plus $n \times$ cell size (Sontek 2000)]. Burst mean correlations increase with distance from the transducer, particularly when bottom orbital velocity is large. The range of reduced correlations and low-biased mean velocities is generally consistent with the range for the near-field acoustic effect indicated by Zedel et al. (1996), although low-biased mean velocities extend into cell 3 in some bursts.

Gartner and Ganju (2003) found a low bias in measured current speed near the transducer similar to that evident in Figs. 9a-g, using 1200-kHz RD Instruments ZedHed and conventional Workhorse ADCPs in a pulsecoherent mode. The bias increased with current speed, 
a) RMS error, $V$ east

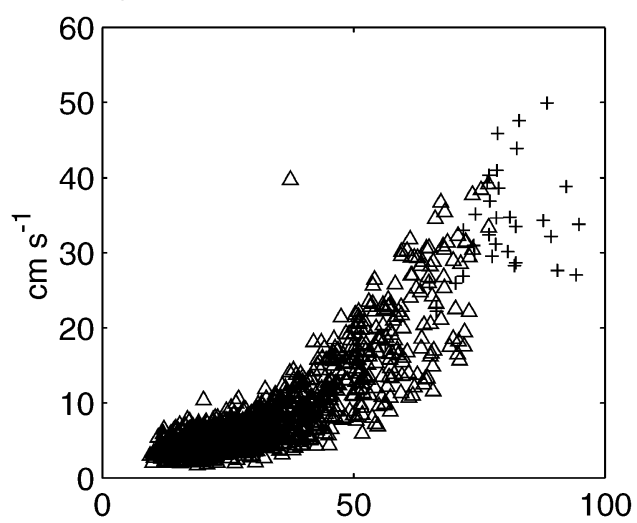

b) RMS error, $V$ north

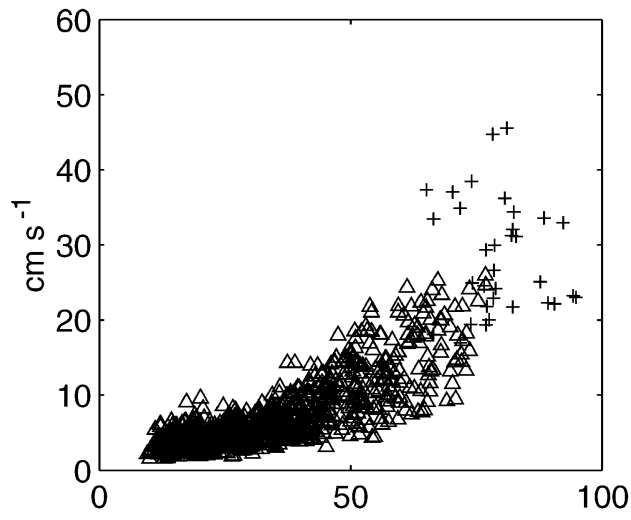

c) RMS error, $V$ vert.

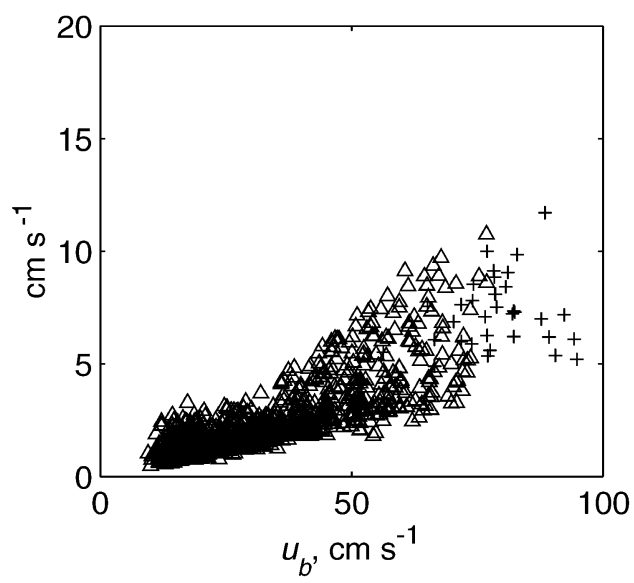

FIG. 7. The rms error vs bottom orbital velocity for (a) east velocity, (b) north velocity, and (c) vertical velocity. Bursts with more than $2 \%$ velocities $>120 \mathrm{~cm} \mathrm{~s}^{-1}$ marked by + .

and extended as far as $0.5 \mathrm{~m}$ from the transducer in a unidirectional current of $\sim 1 \mathrm{~m} \mathrm{~s}^{-1}$. The authors attributed the bias to redirection of flow around the transducer and noted that it was probably not due to decorrelation because the percentage of good pings was similar throughout the profile. We did observe decorrela- a) Error in $u_{b}$

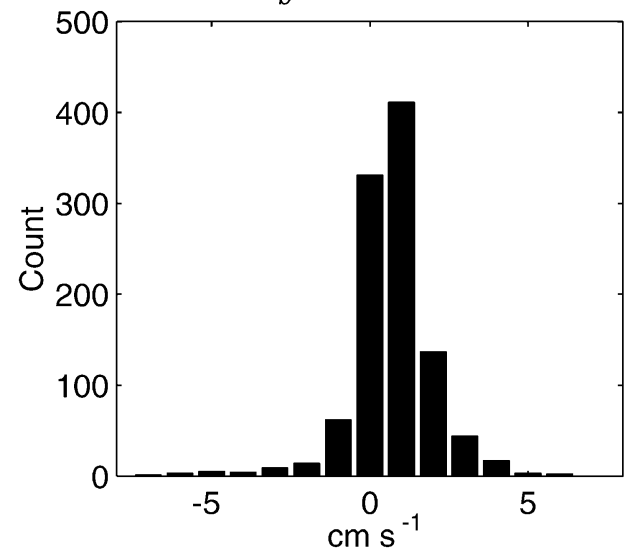

b) Error in $u_{b}$

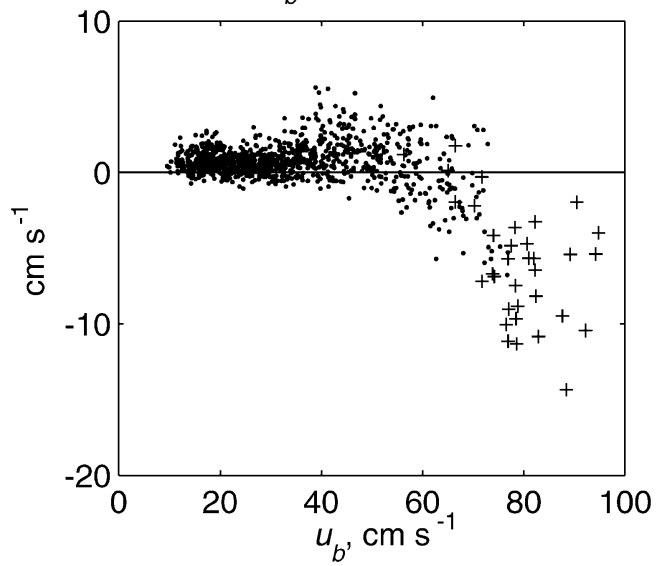

c) Percent error in $u_{b}$

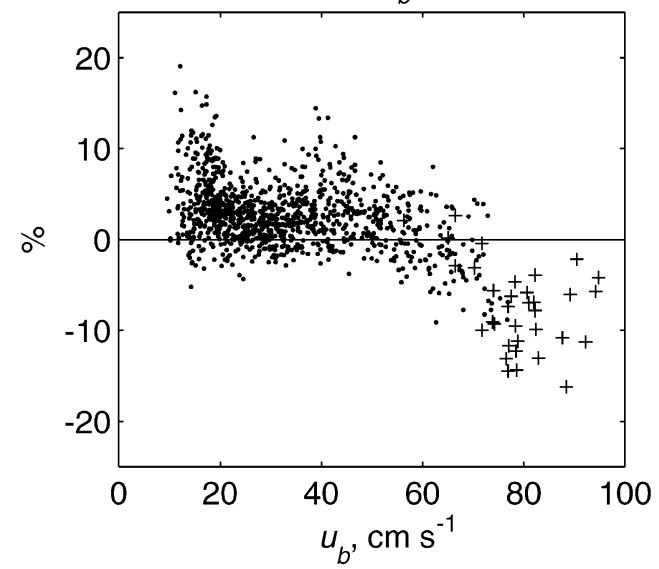

FIG. 8. Error in bottom orbital velocity $u_{b}$ from PCADP cell 5. (a) Histogram of error in $u_{b}$ with $1 \mathrm{~cm} \mathrm{~s}^{-1}$ velocity bins, (b) error in $u_{b}$ vs $u_{b}$ measured by the ADVF, and (c) percent error in $u_{b}$ vs $u_{b}$ measured by the ADVF. Bursts with more than $2 \%$ velocities $>120 \mathrm{~cm}$ $\mathrm{s}^{-1}$ marked by + , and not included in (a).

tion, which cannot be explained by redirection of the flow around the transducer. Increased turbulence in the flow around the instrument may contribute to the observed decorrelation, but the increase in low bias with 
TABLE 3. Mean and std dev of burst mean error $(e)$ and rmse (in $\mathrm{cm} \mathrm{s}^{-1}$ ) with no ambiguity error correction, Sontek's ambiguity error correction, and our ambiguity error correction, for 35 bursts.

\begin{tabular}{|c|c|c|c|c|c|c|}
\hline \multirow{2}{*}{$\begin{array}{c}\text { Velocity } \\
\text { component }\end{array}$} & \multicolumn{2}{|c|}{ No correction } & \multicolumn{2}{|c|}{ Sontek's method } & \multicolumn{2}{|c|}{ Our method } \\
\hline & Mean & Std dev & Mean & Std dev & Mean & Std dev \\
\hline & \multicolumn{6}{|c|}{ Burst mean errors } \\
\hline East & 1.6 & 3.8 & -0.7 & 2.0 & -0.2 & 1.1 \\
\hline North & 0.1 & 3.6 & 1.1 & 3.0 & 0.0 & 0.6 \\
\hline Vertical & 1.1 & 0.9 & 1.0 & 0.9 & 0.8 & 0.8 \\
\hline \multirow[t]{2}{*}{ Horizontal speed } & -1.4 & 3.1 & -1.7 & 2.8 & 0.2 & 0.7 \\
\hline & \multicolumn{6}{|c|}{ Root-mean-square errors } \\
\hline East & 26.7 & 13.8 & 30.0 & 15.2 & 16.0 & 8.7 \\
\hline North & 16.7 & 6.2 & 19.7 & 9.7 & 11.4 & 5.5 \\
\hline Vertical & 4.4 & 1.7 & 5.6 & 2.3 & 4.2 & 1.9 \\
\hline
\end{tabular}

decreasing current speed indicates that turbulence is not the primary cause of the decorrelation. Note that the PCADP (10-cm diameter and 23-cm height) is significantly smaller than the Workhorse ADCP (typically
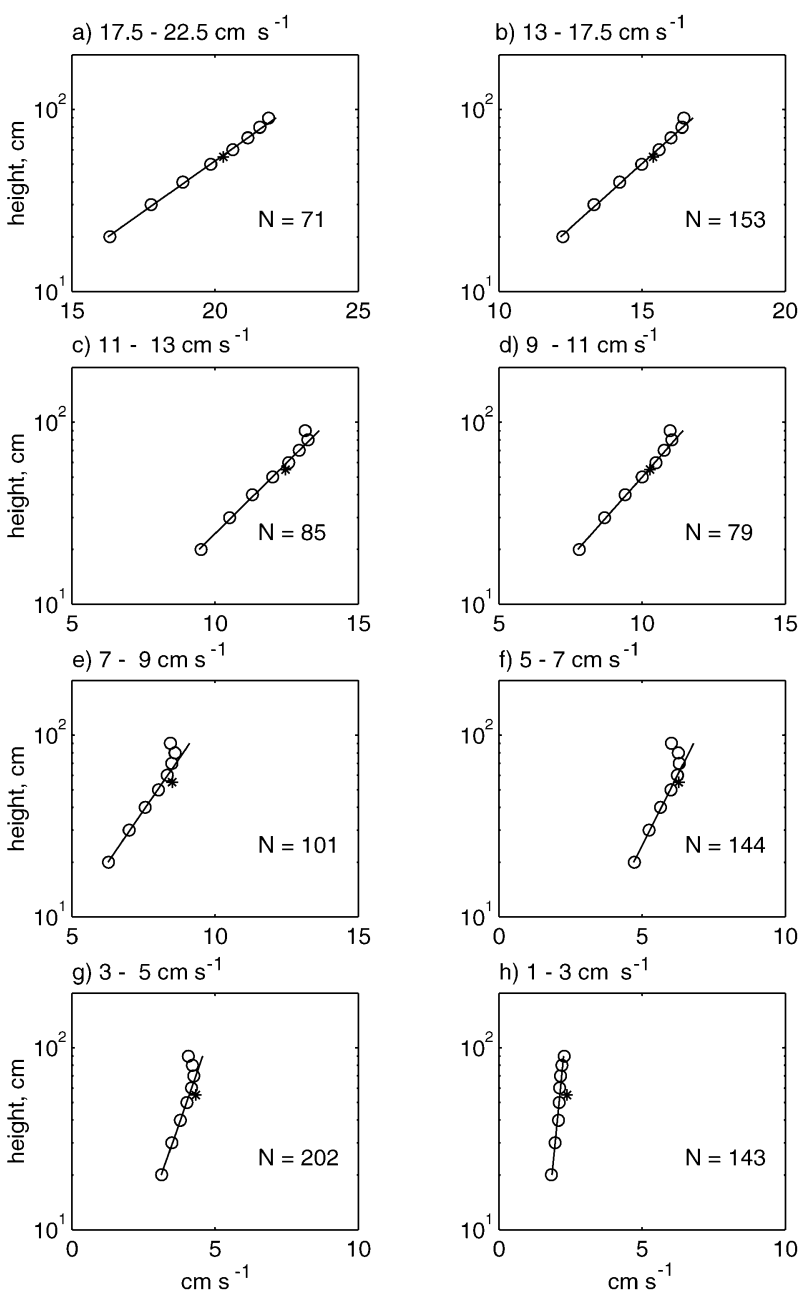

FIG. 9. Average burst mean profile measured by PCADP and by $\operatorname{ADVF}(*)$, for eight ranges of burst mean speed measured in cell 5 . Lines are predicted profiles based on logarithmic fit to speeds in the bottom 5 cells. 23-cm diameter and 40-cm height) and thus disturbs the flow less.

The variation in wave orbital velocity over the vertical range of our measurements $\left(\sim 0.1 \mathrm{~cm} \mathrm{~s}^{-1}\right.$ based on linear wave theory) is less than the precision of our velocity measurements, so measured bottom orbital velocity $u_{b}$ should be uniform with depth. Bursts were grouped into categories based on $u_{b}$ in cell 5 to evaluate average profiles of $u_{b}$. Profiles of average $u_{b}$ are not uniform with depth but are concave, with minimum $u_{b}$ midprofile (Fig. 10). In the less energetic wave categories, mean $u_{b}$ does not vary with depth in the bottom half, but increases at the top of the profile (Figs. 10f-h). Note that the scales of the $x$ axes in Fig. 10 emphasize the variation of $u_{b}$ with depth: the range is less than $\pm 5 \%$ of the mean (except for the top cell in the less energetic categories). The PCADP estimates of average $u_{b}$ are consistently greater than those of the ADVF, but the difference is usually less than $1 \mathrm{~cm} \mathrm{~s}^{-1}$. Nevertheless, the consistent shape of the profiles for the eight categories indicates that the variation with depth is not random error.

The noise level in the velocity data is higher at the top of the profile, which is a likely cause for the increase in $u_{b}$ and decrease in mean speed in this region. Noise contributes to variance, which is directly related to $u_{b}$ [Eq. (1)]. Power spectra of wave velocities in a typical burst show that the energy in frequencies higher than $0.25 \mathrm{~Hz}$ decreases with distance away from the transducer (Fig. 11c). Possible sources of energy in this range of frequencies are turbulence and instrument noise. The portion of spectra dominated by turbulence has a slope of $-5 / 3$, according to Kolmogorov's law (Kundu 1990). Comparison with the dashed line in Fig. 11c shows that the turbulence portion of the spectra is not resolved. The PCADP spectra transition directly from energy associated with waves to the flat profile characteristic of noise. The ADV spectrum indicates that the ADV is resolving turbulent fluctuations at frequencies between 0.4 and $0.8 \mathrm{~s}^{-1}$; this range is above that resolved by the PCADP, for the most part. In the cells closest to the transducer, the spectra are dominated by noise down to $0.25 \mathrm{~s}^{-1}$ and 

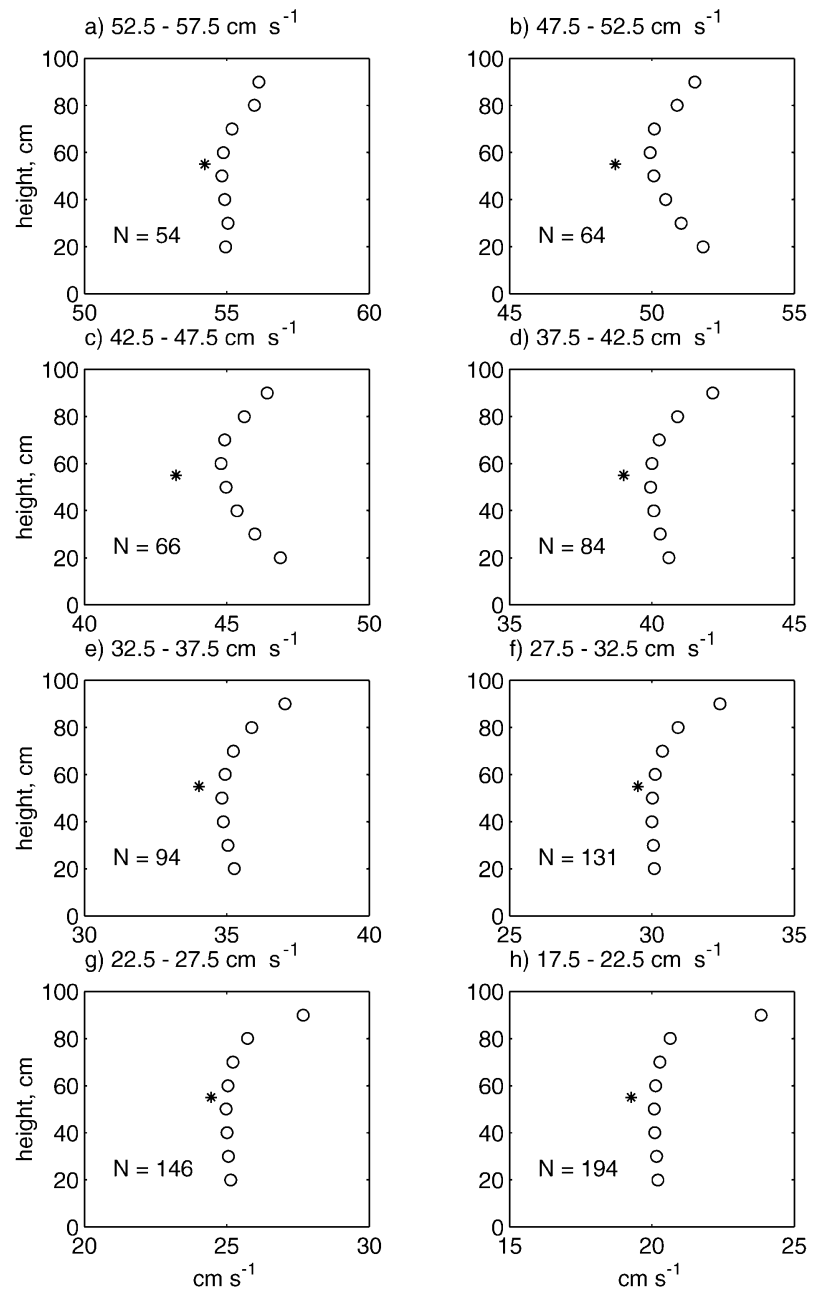

FIG. 10. Average bottom orbital velocity $u_{b}$ measured by PCADP and by $\operatorname{ADVF}(*)$ for eight ranges of $u_{b}$ measured in cell 5 .

any turbulence induced by flow around the transducer cannot be detected. In the cells closer to the bed, the noise is less energetic and is limited to higher frequencies. We conclude that the apparent increase in $u_{b}$ and the low bias in mean speed at the top of the profile are primarily attributable to increased instrument noise close to the transducer. The increased noise is likely caused by decorrelation due to the near-field acoustic effect discussed earlier. The increase in $u_{b}$ in the lower half of the profile, on the other hand, is not explained by high-frequency energy, and requires further investigation. The increase in turbulence near the bed does not produce enough highfrequency energy to exceed the level seen in cell 5.

\section{Friction velocity due to current}

A common motivation for measuring velocity profiles in the bottom boundary layer is to estimate friction velocity and apparent roughness. We calculated friction velocity due to current $u_{* c}$ and apparent roughness $z_{0 a}$ from the PCADP burst mean profiles using the law of the wall. The PCADP measures the distance from the transducer to the bed (accuracy of $\pm 1 \mathrm{~cm}$ ) at the beginning of each burst. Actual measured heights for each burst were used in fitting the data to a logarithmic curve, to account for changes in elevation due to settling and periodic erosion. The bottom five cells were always used, and cells above that were sequentially added if they increased $R^{2}$ between the data and the fitted logarithmic curve. The log fits were used to estimate $u_{* c}$ and $z_{0 a}$ if $R^{2} \geq 0.96$ and burst mean speed $\bar{s} \geq 5$ $\mathrm{cm} \mathrm{s}^{-1}$ in cell 5; 407 out of 769 bursts in deployment 1 and 409 of the 692 bursts in deployment 2 (56\% of all bursts, and $92 \%$ of bursts with $\bar{s} \geq 5 \mathrm{~cm} \mathrm{~s}^{-1}$ ) met the criteria.

Predictions of the Grant-Madsen (GM) model (Grant and Madsen 1979; Madsen 1994) are consistent with the $u_{* c}$, and $z_{0 a}$ values calculated from the PCADP data (Fig. 12). The GM model predicts $u_{*_{c}}, z_{0 a}$, and friction velocity due to current and waves $u_{* c w}$ from a reference velocity, reference depth, bottom orbital velocity, the angle between waves and currents, and the inner (equivalent Nikuradse) roughness $k_{B}$. Inner roughness $k_{B}$ is influenced by bedforms and other factors, and thus changes over time. Figure 12 shows a range of predictions with a lower bound based on $k_{B}=0.2 \mathrm{~mm}$ and an upper bound based on $k_{B}=5 \mathrm{~cm}$ (bed sediments have $D_{85}=0.18 \mathrm{~mm}$ ). Both $u_{* c}$ and $z_{0 a}$ fall within the predicted range most of the time. Comparison with the time series of bottom orbital velocity in Fig. 1a shows that $u_{* c}$ increased as expected during periods of high burst mean speed and $u_{b}$ (9 and 15-17 May, 28-29 June). The high percentage of $\log$ fits with $R^{2} \geq 0.96$ and the agreement between $u_{* c}$ calculated from the velocity profiles and the GM model demonstrate that the PCADP can be successfully used to estimate friction velocity and apparent roughness in wave-dominated environments.

\section{Summary and conclusions}

A PCADP was used to measure velocity profiles in the bottom boundary layer on the inner shelf (mean depth $9 \mathrm{~m}$ ) off the coast of southwest Washington during the summer of 2001. Current speeds up to $40 \mathrm{~cm} \mathrm{~s}^{-1}$ and wave orbital velocities up to $95 \mathrm{~cm} \mathrm{~s}^{-1}$ occurred during the experiment, providing rigorous conditions for evaluating the PCADP. Velocities were measured in eight $10-\mathrm{cm}$ (nominal) cells within $1 \mathrm{~m}$ of the bed, with a 10-cm blanking distance. An ADVF was used to evaluate the accuracy of the PCADP based on the results of 1043 synchronous bursts. An algorithm to correct PCADP ambiguity error was developed, which substantially reduced the rms errors, particularly at high orbital velocities. The average error in burst mean speed is $-0.4 \mathrm{~cm} \mathrm{~s}^{-1}$ (std dev $=0.8$ ). The rms error for the PCADP has a mean of $8.6 \mathrm{~cm} \mathrm{~s}^{-1}$ (standard deviation $=6.5$ ) for eastward velocities (predominant direction of waves), $6.6 \mathrm{~cm} \mathrm{~s}^{-1}$ (standard deviation $=4.4$ ) for 
a) $u_{b}$

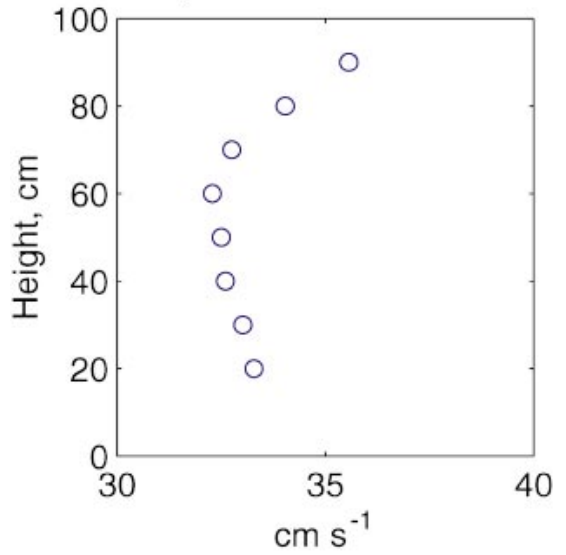

b) Mean speed

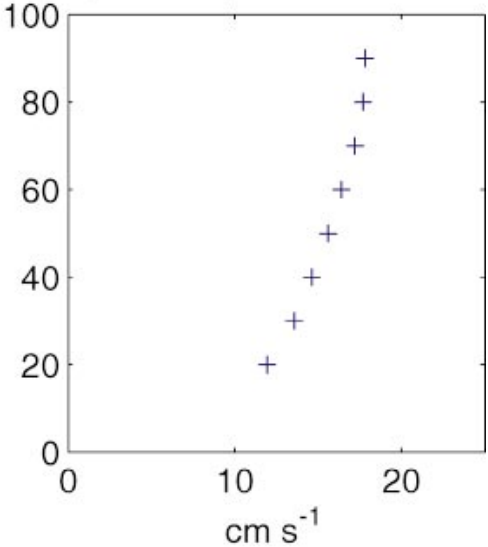

c) Spectra of wave velocities in 5 cells and ADV

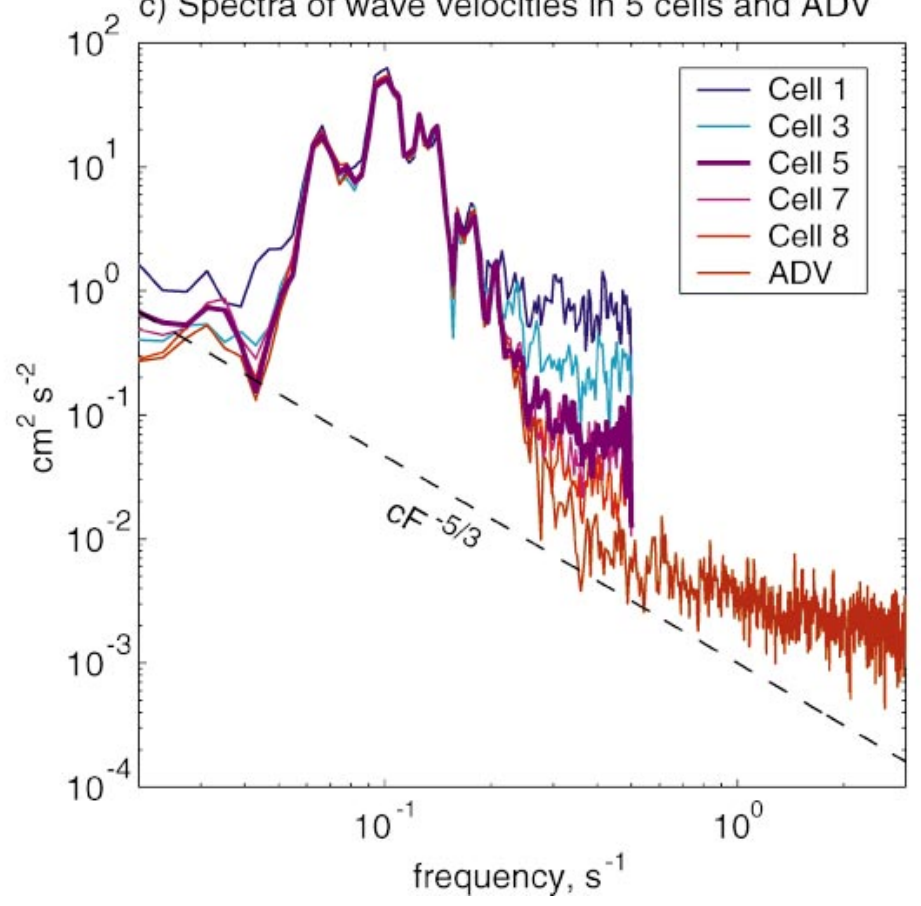

FIG. 11. Profiles of (a) bottom orbital velocity and (b) burst mean speed; (c) power spectra of wave velocities for five cells and ADV for burst collected at 0700 UTC 6 May 2001; dashed line has $-5 / 3$ slope characteristic of turbulence portion of spectrum. Cell 1 is closest to transducer; cell size is $\sim 10 \mathrm{~cm}$.

northward velocities, and $2.4 \mathrm{~cm} \mathrm{~s}^{-1}$ (standard deviation $=1.6)$ for vertical velocities. The mean error in bottom orbital velocity $u_{b}$ is $0.7 \mathrm{~cm} \mathrm{~s}^{-1}$ (standard deviation $=$ 1.3). Both burst mean and rms errors have higher means and standard deviations for bursts with $u_{b} \geq 50 \mathrm{~cm} \mathrm{~s}^{-1}$, indicating that the ambiguity error correction algorithm was not always successful.

Average profiles of burst mean speed $\bar{s}$ for seven categories of $\bar{s}$ fit logarithmic profiles with $R^{2} \geq 0.99$, based on the five depth cells farthest from the transducer. In the cells closest to the transducer, the burst mean speed is lower than predicted by the logarithmic profiles. Average $u_{b}$ for eight categories of wave energy is not uniform with depth, but increases at the top and bottom of the profile. While the variation in $u_{b}$ with depth appears to be systematic, it is typically less than $5 \%$ of the mean. Burst mean correlations are reduced in the cells closest to the transducer, and the noise level in the instantaneous velocities is high. Thus, the depressed burst mean speeds and elevated $u_{b}$ at the top of the profiles appear to be caused by poor data quality rather than flow disturbance. The range of the reduced cor- 
a) Friction velocity due to current
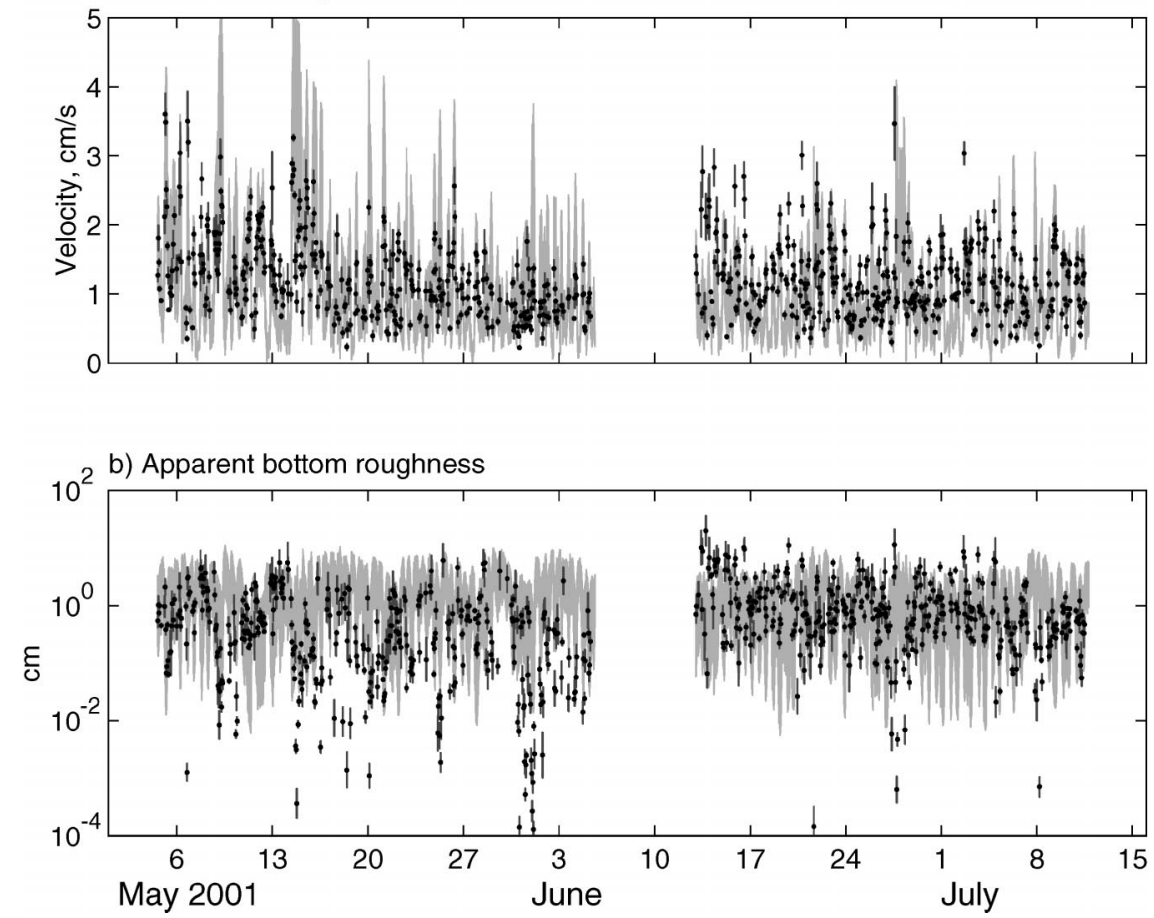

FIG. 12. (a) Friction velocity due to current and (b) apparent bottom roughness. Estimates from $\log$ fits of data are shown by black points with error bars. Pale gray shaded region is bounded by Grant-Madsen (1979) model predictions for $k_{B}=0.2 \mathrm{~mm}$ and $k_{B}=5 \mathrm{~cm}$.

relations is consistent with the expected range of the near-field acoustic effect identified by Zedel et al. (1996): $30 \mathrm{~cm}$ from the transducer for this instrument.

Profiles of burst mean speed were used to estimate friction velocity and apparent bottom roughness using the law of the wall. Ninety-two percent of profiles with a burst mean speed $\geq 5 \mathrm{~cm} \mathrm{~s}^{-1}$ fit logarithmic profiles with correlation coefficients $R^{2} \geq 0.96$; however, the top 2-3 cells were frequently not used in the logarithmic fits because they decreased $R^{2}$. The $u_{* c}$ and $z_{0 a}$ values calculated from the $\log$ fits were consistent with predictions of the Grant-Madsen wave-current boundary layer model.

With $10-\mathrm{cm}$ cells the PCADP accurately measures burst mean and instantaneous velocities, even in wave velocities as high as $60 \mathrm{~cm} \mathrm{~s}^{-1}$. However, velocities close to the transducer are frequently too noisy to produce accurate instantaneous or burst mean velocities. We recommend using a blanking distance of $20 \mathrm{~cm}$ and carefully evaluating data from the top cell. For the same reason, it is important to increase the blanking distance for the resolution pulse from its default value of $10 \mathrm{~cm}$. We used a resolution blanking-distance of $24 \mathrm{~cm}$, and removed spikes in the resolution velocity before using it to correct ambiguity errors.

Acknowledgments. Thanks to Laura Landerman, Joanne Ferreira, Keith Kurrus, and Kevin Redman for help with data collection, and to Vadim Polonichko for explanations of the principles and operation of the PCADP. Thanks to Mike Simpson of the USGS Water Resources Division for helpful discussions on the principles of pulse-coherent Doppler systems. Marinna Martini, Jingping $\mathrm{Xu}$, and two anonymous referees provided helpful reviews of the manuscript. This work was funded by the U.S. Geological Survey as part of the Southwest Washington Coastal Erosion Study. Any use of trade, product, or firm names in this paper is for descriptive purposes only and does not imply endorsement by the U.S. Government.

\section{REFERENCES}

Cacchione, D. A., and D. E. Drake, 1982: Measurements of stormgenerated bottom stress on the continental shelf. J. Geophys. Res., 87, 1952-1960.

Cheng, R. T., C.-H. Ling, and J. Gartner, 1999: Estimates of bottom roughness length and bottom shear stress in South San Francisco Bay, California. J. Geophys. Res., 104, 7715-7728.

Drake, D. E., D. A. Cacchione, and W. D. Grant, 1992: Shear stress and bed roughness for combined wave and current flows over a rippled bed. J. Geophys. Res., 97, 2319-2326.

Gartner, J. W., and N. K. Ganju, 2003: A preliminary evaluation of near-transducer velocities collected with low-blank acoustic Doppler current profiler. Proc. Hydraulic Measurements and Experimental Methods Conf., Estes Park, CO, ASCE, CD-ROM.

Grant, W. D., and O. S. Madsen, 1979: Combined wave and current interaction with a rough bottom. J. Geophys. Res., 84C, 17971808 . 
— A. J. Williams III, and S. M. Glenn, 1984: Bottom stress estimates and their prediction on the northern California continental shelf during CODE-1: The importance of wave-current interaction. J. Phys. Oceanogr., 14, 506-527.

Gross, T. F., and A. R. M. Nowell, 1983: Mean flow and turbulence scaling in a tidal boundary layer. Cont. Shelf Res., 2, 109-126.

Hurther, D., and U. Lemmin, 2001: A correction method for turbulence measurements with a 3D acoustic Doppler velocity profiler. J. Atmos. Oceanic Technol., 18, 446-458.

Kundu, P. K., 1990: Fluid Mechanics. Academic Press, 638 pp.

Lhermitte, R., and R. Serafin, 1984: Pulse-to-pulse coherent Doppler sonar signal processing techniques. J. Atmos. Oceanic Technol., 1, 293-308.

Lohrmann, A., B. Hackett, and L. P. Røed, 1990: High resolution measurements of turbulence, velocity and stress using a pulseto-pulse coherent sonar. J. Atmos. Oceanic Technol., 7, 19-37.

Madsen, O. S., 1994: Spectral wave-current bottom boundary layer flows. Proc. 24th Int. Conf. on Coastal Engineering, Kobe, Japan, ASCE, 384-398.

Nystrom, E. A., K. A. Oberg, and C. R. Rehmann, 2003: Measurement of turbulence with acoustic Doppler current profilers-Sources of error and laboratory results. Proc. Hydraulic Measurements and Experimental Methods Conf., Estes Park, CO, ASCE, CDROM.

Sontek, 1997: Acoustic Doppler Velocimeter ADV principles of operation. Sontek, $14 \mathrm{pp}$

_ 2 2000: Acoustic Doppler Profiler operation manual, firmware version 6.7. Sontek, $96 \mathrm{pp}$

Voulgaris, G., and J. H. Trowbridge, 1998: Evaluation of the acoustic Doppler velocimeter (ADV) for turbulence measurements. J. Atmos. Oceanic Technol., 15, 272-289.

Zedel, L., A. E. Hay, R. Cabrera, and A. Lohrmann, 1996: Performance of a single-beam pulse-to-pulse coherent Doppler profiler. IEEE J. Oceanic Eng., 20, 290-297. 